\title{
Planejamento e delineamento de experimentos probabilísticos para o Ensino Fundamental I
}

\author{
Paulo César Oliveira \\ Júlio César Pereira \\ Universidade Federal de São Carlos
}

\section{Resumo}

Apresentamos fragmentos de um processo de aprender, aprender a ensinar e ensinar noções de estatística e probabilidade por parte de professoras que atuam nas séries iniciais do ensino fundamental. Esta temática foi inserida nos currículos brasileiros a partir de 1998, e muitos professores em atuação não tiveram em sua vida escolar e profissional uma aprendizagem sistematizada desse assunto. Uma forma de contribuir com estes profissionais é a publicação de artigos científicos, porém Guimarães et al. (2009) constataram que no período de 2001 a 2006 foram publicados apenas sete artigos relacionados a este contexto. Neste sentido, nossa contribuição dar-se-á pela reflexão sobre o processo de experimentação e suas implicações para a aprendizagem.

Palavras-chave: Estatística. Probabilidade. Ensino Fundamental.

1. Este trabalho contou com o apoio financeiro do Conselho Nacional de Desenvolvimento Científico e Tecnológico - CNPq. 


\section{Planning and design of probabilistic experiments for Elementary Education I}

We present fragments of a process of learning, learning to teach and teaching concepts of probability and statistics, involving teachers who work in elementary schools. This subject has been included in the educational curriculum in Brazil since 1998 and many working teachers have not undergone a process of systematic learning of it in their school and working life. One way of supporting these professionals is by publishing scientific papers. However, Guimarães et al. (2009) found that between 2001 and 2006 only seven papers relating to this context were published. Hence, our contribution will be to reflect on the experimentation process and its implications for learning.

Keywords: Statistics. Probability. Elementary school.

\section{Planeamiento y delineamiento de experimentos probabilísticos para la enseñanza primaria}

Se presentan fragmentos de un proceso de aprendizaje, el aprendizaje para enseñar, y enseñar nociones de probabilidad y estadística por parte de los profesores que trabajan en los primeros grados de la escuela primaria. Este tema se incluyó en los planes de estudio de Brasil desde 1998, y muchos profesores que actuaban en la escuela, no tuvieron en su vida escolar y profesional un aprendizaje sistemático sobre este tema. Una forma de contribuir con estos profesionales es la publicación de artículos científicos, sin embargo, Guimaraes et al. (2009) verificó que en el período de 2001 hasta 2006 solamente fueron publicados siete artículos relacionados a este contexto. En ese sentido, nuestra contribución se dará sobre la reflexión en el proceso de experimentación y sus implicaciones en el aprendizaje.

Palabras clave: Estadística. Probabilidad. Escuela primaria. 


\section{Introdução}

As orientações curriculares para a disciplina matemática no âmbito do ensino fundamental e médio, mais especificamente para o ensino de estatística e probabilidade, aparecem descritas no bloco de conteúdo intitulado Tratamento das Informações. Tal nomeação, contida nos Parâmetros Curriculares Nacionais de Matemática, é justificada pela necessidade de o aluno ser capaz de ler e interpretar informações veiculadas nos meios de comunicação e, a partir daí, tomar decisões e fazer previsões.

Oliveira (2003) assim como Lopes e Carvalho (2005) enfatizam o desenvolvimento de estudos em estatística e probabilidade, desde os anos iniciais de escolaridade, pautados no processo de experimentação, o qual pode ser aplicado tanto no registro e análise de observações quanto em situações que permitem o confronto ou superação do determinismo a favor da aleatoriedade. No entanto, a presença desses estudos no decorrer das aulas de matemática não é uma simples questão de inserção de novos conteúdos, mas a inclusão de uma forma de pensamento diferente da que tradicionalmente defrontamos no cotidiano do contexto escolar. Isto, principalmente para os professores dos anos iniciais do ensino fundamental, cria uma sensação de insegurança, em função das deficiências contidas em sua formação profissional (Azcárate, 1998). Lopes (2010) ratifica que os temas voltados à estatística e probabilidade têm sido distribuídos de forma inadequada nos programas de ensino. A falta de domínio teóricometodológico do professor sobre os conceitos estatísticos e probabilísticos compromete a eficácia do tratamento dos mesmos em sala de aula. Contudo, a escola é a instância capaz de proporcionar uma visão mais equilibrada da realidade, contemplando, por meio da educação formal, o ato de pensar sob a perspectiva do provável, do acaso.

Este artigo tem por objetivo discutir a importância do processo de experimentação, a partir do recorte de atividades desenvolvidas durante os períodos letivos de $2001 \mathrm{e}$ 2002, numa relação de parceria com duas professoras que ministram aulas de matemática nos primeiros anos do ensino fundamental, em uma escola municipal de Hortolândia, localizada no interior do Estado de São Paulo'.

\section{Márcia e Gildete: quem são estas professoras-parceiras?}

Estas duas professoras - cujos nomes verdadeiros são publicados neste artigo com a autorização devida - têm em seu desenvolvimento profissional a influência do curso de magistério realizado. Assunção (1996), no intuito de compreender o cotidiano da

1. Dados empíricos deste artigo são oriundos da tese de doutorado do primeiro autor, defendida em 2003. A pesquisa não contou com financiamento. 
professora e quem é a mulher-professora que atua neste segmento escolar, constatou que, na maioria dos seus sujeitos de pesquisa, a formação profissional do magistério fora precária. As constatações desta autora também são presentes nas falas de nossas professoras-parceiras. Elas foram categóricas em expressar a precariedade na relação teoria-prática durante o curso, a qual foi constatada no momento em que assumiram pela primeira vez uma sala de aula. A defasagem desta relação, na óptica das professoras, foi associada à realização do estágio: para Gildete, o período destinado à prática foi curto; para Márcia, o estágio que realizou serviu para aprender o que não deveria fazer.

0 fato de o professor em início de carreira encontrar, muitas vezes, uma realidade escolar diferente daquela idealizada nas aulas do curso de formação, permeada pelo dilema indisciplina, situação de fracasso escolar - exemplos estes destacados por Márcia -, "pode levá-lo a negar a teoria como uma importante fonte de referência para a ação pedagógica" (Moura, 1999, p. 8). No momento atual, ao pensar sobre a realidade escolar partilhada por estas professoras, ambas consideram que a unidade escolar onde atuam proporciona boas condições para o exercício da docência. Márcia destaca que a escola, enquanto instituição, não preza apenas o cumprimento e determinação de regras e normas; ao contrário, preza o público que atende.

Para a professora Gildete, o desenvolvimento da criança não se dá apenas pela transmissão de conhecimento, é preciso formar e informar o aluno. Em termos de argumentações, Márcia expôs uma concepção de mundo idealista em seu saber-fazer, quando afirma que seu papel como educadora é construir um mundo melhor, uma realidade um pouco melhor, formar cidadãos capazes de criticar, de ver erros, de tentar melhorar enquanto pessoas. Complementa, por meio de sua fala, que isto é possível se ela própria puder tornar-se amanhã uma pessoa melhor do que já foi. Como já ressaltamos, a escola pode ser um local onde ensinar e aprender são possibilidades reais. De acordo com Nóvoa (1995, p. 36), “[...] o aprender contínuo é essencial em nossa profissão". Tal aprendizado deve concentrar-se em dois pilares: na própria pessoa do professor, como agente, e na escola, como lugar de crescimento profissional permanente. Mesmo que um desses pilares possua um alicerce frágil, o profissional não pode deixar de ter em mente que ele é responsável pela sua formação.

No caso de nossas professoras, Márcia concluiu o curso de licenciatura em letras, e Gildete, o curso de pedagogia. Apesar do grau de licenciatura, essas professoras têm ciência de que, frente às novas demandas educacionais para a educação básica, em especial a inclusão do Tratamento da Informação, há necessidade de se transpor esse obstáculo no exercício da docência. Esse obstáculo é caracterizado pela carência de conceitos estatísticos e probabilísticos, e, em termos didáticos, esta deficiência sobressai por conta da necessidade do domínio teórico-metodológico dos temas em questão. 
A partir dos relatos orais de Márcia e Gildete, podemos apontar que elas achavam que nunca haviam abordado temas da estatística e probabilidade em suas aulas. Se foram trabalhados em sala de aula, não sabiam que estavam desenvolvendo atividades pertinentes aos temas, pois, enquanto alunas, nunca estudaram esses assuntos em seu processo de formação².

\section{A relação entre os protagonistas da investigação: episódios desse processo}

Um objetivo parcial da pesquisa foi partilhar saberes produzidos e mobilizados por essas professoras, no e para o seu trabalho docente, envolvendo o conceito de probabilidade. Não desejávamos que a forma de estruturar o trabalho de campo se desviasse do princípio básico da pesquisa, ou seja, que o investigar com o professor ficasse apenas como pretensão e, na realidade, a pesquisa tomasse o rumo de investigar o professor. Nosso percurso metodológico demarcou uma pesquisa de natureza qualitativa, mais especificamente um estudo de caso, pelo fato de utilizarmos um repertório de informações singulares, produzido a partir da construção e (de)construção de saberes, considerando que são "imprevisíveis as relações que cada sujeito estabelecerá entre o novo que apreende e sua própria história" (Collares; Moysés; Geraldi, 1999, p. 208).

A produção de resultados aleatórios a partir do processo de experimentação probabilística visou proporcionar para cada uma de nossas professoras-parceiras uma experiência única, pessoal e intransferível, porque cada resultado é irreversível, mesmo sendo um processo que permite inúmeras repetições. Larrosa (2002, p. 27) fornece-nos contribuições a este respeito quando afirma: “[...] se a experiência não é o que acontece, mas o que nos acontece; duas pessoas, ainda que enfrentem o mesmo acontecimento, não fazem a mesma experiência. 0 acontecimento é comum, mas a experiência é para cada qual sua, singular".

No decorrer de nossos encontros, quatros tipos de atividades foram marcantes. Uma delas se constituiu em sessões de estudos que envolveram discussões conceituais de probabilidade. Decorrente destas sessões, uma segunda modalidade de atividade foi o planejamento e a execução de atividades para a sala de aula. A terceira atividade constituiu-se na realização de duas reuniões destinadas à avaliação do trabalho em sala de aula, bem como das sessões de estudo. Finalmente, por iniciativa dos pesquisa-

2. O repertório de informações obtido em entrevistas com essas professoras foi imprescindível para o planejamento inicial dos nossos encontros.. 
dores, foi proposto às professoras-parceiras responder, por escrito, um questionário elaborado com o objetivo de sistematizar o trabalho desenvolvido e despertar reflexões sobre o bloco tratamento de informação, no aspecto tanto conceitual quanto curricular.

Para atender o objetivo deste artigo, selecionamos dois episódios, com o propósito final de abordar a representação numérica no intervalo de zero a um, como valores de probabilidade. Apresentamos o planejamento, execução e discussão sobre um experimento probabilístico que gerou uma sequência de resultados a partir da extração de bolas, e também sobre outro experimento cujos resultados obtidos decorreram de sucessivos lançamentos de tachinha (percevejo). Os objetos tachinha e bola, utilizados em processos de experimentação aleatória, geram dois fenômenos com concepções probabilísticas distintas. No caso da extração de bolas, a produção de resultados a partir da realização do experimento induz o sujeito à realização de cálculos de probabilidade que levam em conta a simetria física do objeto. Já na utilização da tachinha, a percepção da assimetria do objeto instiga a análise da ausência da equiprobabilidade para os eventos elementares "ponta para cima" e "ponta para baixo", que identifica a posição do objeto ao tocar o solo.

\section{Bastidores e cenas do $1^{\circ}$ episódio}

Para o nosso primeiro encontro de estudos em probabilidade planejamos, juntamente com as professoras-parceiras, o que seria relevante para desencadearmos um processo de aprendizagem nessa temática. A dinâmica de cada novo encontro foi construída a partir da reflexão sobre os fatos ocorridos no encontro anterior. Neste sentido, o montante de informações produzidas no decorrer do trabalho de campo foi sendo acumulado por aquilo que o pesquisador denominou de ritual: transcrição de toda a comunicação gerada em cada encontro, pelo uso tanto de gravador quanto de diário; em seguida, uma reunião presencial entre pesquisador e orientadora para sistematização da análise do material obtido, com sugestões de encaminhamentos para uma reunião de planejamento entre pesquisador e professoras-parceiras. Na reunião de planejamento com nossas professoras, construíamos a dinâmica do novo encontro. Esta forma artesanal de construção de cada encontro do trabalho de campo de nossa pesquisa, mediante o cumprimento do ritual, justifica-se pelo fato de que o processo de aprender sofre construção e (de)construção de saberes, à medida que os protagonistas envolvidos entendem que a parceria é permeada por um processo de formação contínua.

No exercício de docência dessas professoras-parceiras, o livro didático é a fonte de consulta mais acessível, imediata, e por diversas vezes uma fonte de pesquisa. Bastos 
(2004) publicou obra em que expressa preocupação quanto ao fato de que o livro didático é escrito de acordo com a concepção do autor sobre o processo ensinoaprendizagem da matemática, e isto pode levar o professor a exercer uma prática que priorize a transmissão ao aluno por meio da exposição e resolução de exercícios-padrão. A seguir, apresentamos um exemplo do que seria um exercício-padrão sugerido pelas nossas professoras-parceiras, a partir do enunciado de um livro didático compulsado em nosso primeiro encontro.

Igor e Karen introduziram duas bolas, uma branca (B) e a outra azul (A), dentro de um saco plástico não transparente. Depois, eles fizeram dez retiradas, sempre recolocando a bola de volta no saco e registrando o resultado. Com base neste enunciado, qual a cor de bola que você acha que saiu mais vezes? Por quê? Em seguida, suponha que os resultados das retiradas foram: B A A B A B A A B A. Como você expressaria esses resultados utilizando frações? (Oliveira, 2003, p. 96).

Tomamos a atitude de instigar o raciocínio de nossas professoras, questionando-as sobre as condições descritas no enunciado para uma possível execução do experimento. Mais especificamente, fizemos dois questionamentos: o primeiro, sobre o uso do saco plástico não transparente, que teve por objetivo evitar a realização de retiradas propositais ou intencionais quanto ao atributo cor; o segundo questionamento foi, na verdade, um alerta sobre a importância do ato de mexer o saco plástico antes de cada retirada, a fim de evitar que o sujeito, ao realizar o experimento, retire intencionalmente uma ou outra bola, por ter memorizado o local onde repusera a bola na extração anterior. Discutimos também sobre a descrição da sequência de resultados de extração de bolas registrada no enunciado. Como síntese desta abordagem, destacamos que a sequência descrita é um exemplar dentre outras, inclusive em relação aos resultados obtidos na realização deste experimento com as professoras.

Finalmente, em termos de cálculo da probabilidade, tratamos da necessidade de se levar em conta tanto o valor teórico, ou seja, aquele pressuposto antes da produção dos resultados da sequência, quanto a estimativa da probabilidade frequentista, fruto do processo de experimentação, a qual será tanto melhor quanto maior o número de repetições do experimento. Este valor teórico na verdade refere-se à definição clássica de probabilidade. Por exemplo, suponha-se uma caixa contendo uma bola vermelha (V), uma branca (B) e uma azul (A). Supondo que as bolas são de mesmo tamanho, mesma massa e mesmo material de confecção (indistinguíveis ao toque), espera-se que $P(V)=P(B)=P(A)=1 / 3$. Porém, esta probabilidade pode ser estimada realizando-se extrações sucessivas vezes. Neste caso, estaria estimando-se a probabilidade frequentista, 
definida como se segue. Seja A um evento qualquer, em que indica o número de ocorrências de $A$ e $n$ o número de repetições independentes do experimento (Magalhães, 2006).

Nesta situação, pode ocorrer que o valor de P(V) não seja 1/3, mesmo se repetindo o experimento nas mesmas condições iniciais, um número muito grande de vezes. Isto pode ocorrer, pois na prática dificilmente teremos bolas perfeitas de mesmo tamanho, mesma massa, entre outros fatores, ou seja, o valor da probabilidade frequentista pode não ser o mesmo valor da probabilidade clássica. Mesmo que os valores teóricos não mudem, na realidade não se pode repetir um experimento infinitas vezes; assim, temse uma diferença entre o real observado <estimativa > e o valor da probabilidade <valor teórico> (Carvalho; Oliveira, 2002). Não devemos interpretar que o fato de se ter uma diferença entre o real e o modelo abstrato seja um argumento para a não realização de experimentos para o ensino e aprendizagem do bloco temático Tratamento da Informação. Por outro lado, julgamos necessário destacar aqui a relevância de se discutirem as condições experimentais. A seguir, apresentamos trechos da comunicação ocorrida neste episódio, os quais serão utilizados na discussão sobre as condições de realização do experimento probabilístico e suas implicações educativas.

01 Paulo: Lendo a questão, que cor vocês acham que sairá mais? Por quê?

02 Gildete: Em 10 retiradas não há a mesma chance, ou pode ter a mesma chance.

03 Márcia: Eu acho que tem a mesma chance.

04 Paulo: Então vamos fazer o experimento. Cada uma faz cinco extrações e não esqueça de registrar para continuarmos a discutir.

Para a realização desse experimento, levamos em conta as condições descritas no enunciado, além de utilizarmos duas bolas de isopor, cada uma com a respectiva identificação (A e B), ambas depositadas em um saco de cor escura e opaca. De comum acordo, cada professora fez cinco extrações de bolas com reposição, gerando ao todo dez resultados: A A B A B A B B B B. 0 primeiro, terceiro, quinto, sétimo e nono resultado foram obtidos por Márcia (subsequência $A B$ B B B), e os outros, por Gildete (subsequência A A A B B). Após o registro destas sequências na lousa, o pesquisador registrou em seu diário, duas observações enunciadas entre as professoras:

05 Gildete: Ao retirar a bola e devolver no mesmo lugar, eu acho que tirei sempre a mesma, mesmo a bola sendo redonda.

06 Márcia: Mexi o saco e tirei as bolas, mas acho que este procedimento não influenciou minhas retiradas. 
Antes de partirmos para a análise das falas, apresentamos estes registros do diário do pesquisador para ratificar o que já escrevemos quanto às condições para a realização do experimento probabilístico. Durante a execução do experimento, constatamos a importância do ato de mexer o saco plástico antes de cada retirada, a fim de evitar a retirada intencional de uma ou outra bola. Isto evidência a importância do delineamento experimental, isto é, dos cuidados necessários ao planejar de forma adequada o experimento a ser realizado. Pensando em nossa investigação, estes cuidados devem ser rotineiros, pois a partilha de saberes, produzidos e mobilizados pelas professorasparceiras, implicará o desenvolvimento de competências dos seus alunos, no decorrer da aprendizagem.

Nos segmentos 2 e 3, verificamos que o uso da palavra "chance" está coerente quando associado à equiprobabilidade ou não dos resultados do experimento com reposição, ou seja, é possível que nas extrações haja a mesma possibilidade de ocorrência ou não. Neste contexto, o uso da palavra chance relaciona-se com ocasião favorável, oportunidade.

Em estatística e probabilidade, certos autores de livros voltados ao público do ensino superior concebem a palavra chance como sinônimo de ocorrência de um evento particular (no caso, a extração de uma bola azul ou branca em uma retirada com reposição). Como exemplo, segue a descrição contida em um destes materiais:

Chance e probabilidade acham-se estreitamente relacionadas. Na realidade, a chance é apenas um método alternativo de exprimir as probabilidades. A única diferença entre chance e probabilidade é que chance compara o número de resultados favoráveis com o número de casos desfavoráveis, ao passo que a probabilidade compara o número de resultados favoráveis com o número total de resultados possíveis (Stevenson, 1981, p. 63).

Em um momento posterior, questionamos sobre como representar numericamente a probabilidade da ocorrência do referido evento:

05 Gildete: 4/10 para a cor branca.

06 Paulo: Como pensou para dizer esta fração?

07 Gildete: Olhei a bolinha branca em relação ao total de retiradas.

08 Márcia: 6/10 para a azul.

Quando pedimos para utilizar frações, por ser um conteúdo tratado essencialmente no ensino fundamental l e, supostamente, uma das formas de representação da probabilidade mais acessível às nossas professoras, a resposta foi dada com base na 
sequência contida na redação do enunciado apresentado. De forma previsível, a representação fracionária fornecida pelas professoras continha a relação parte-todo. A quantificação da probabilidade envolve três quantidades cruciais (duas partes - casos favoráveis e não favoráveis, e o todo - a totalidade dos casos) e as relações entre essas quantidades. Estas relações podem ser estabelecidas tanto na relação parte-todo (comparação entre a parte e o todo) quanto na relação parte-parte (comparação entre as partes) (Spinillo, 1997).

A indagação feita pelo pesquisador envolvendo o uso de fração tolheu a possibilidade de as professoras discutirem a forma de representar o valor da probabilidade. Avaliamos que a pergunta contida no enunciado poderia questionar a necessidade de expressar a probabilidade e não focalizar o uso de frações. Para contornar a situação, o pesquisador instiga o raciocínio das professoras-parceiras por meio de uma nova questão, que desencadeou uma sequência de diálogos:

09 Paulo: Para uma retirada sendo duas bolas, como vocês veem a representação?

10 Gildete: Fiz uma retirada. (Sem olhar, a professora insere a mão na caixa e extrai, ao acaso, a bola branca.) A bola que ficou, esquece! A representação fracionária é 1/1 (registro da professora na lousa).

11 Márcia: ((Ela repete o gesto da Gildete e também extrai a bola branca)). Branca. A representação é 1/1 (lEmbora ela tenha respondido, seu semblante transparece um ar de desconfiança em relação à própria respostal). A fração 6/10 é o que saiu sobre o número de retiradas de uma bola com mesma cor l(A professora retoma sua resposta dada na fala 8)J. Como representar a fração da cor que ficou na caixa? Devolvendo ou não a outra bola? Qual é a diferença de devolver ou não, só para uma retirada?

12 Paulo: Nenhuma! É só uma extração. Vamos estimar antes da retirada?

13 Márcia: 50\%.

14 Gildete: $1 / 2$. Tem como ajudar? Eu represento 1/2 (registro escrito da professora).

14 Paulo: E como fica o 1/1?

15 Gildete: 4/10 considerou o número de retiradas ((referindo-se a sua resposta na fala 5)). 16 Márcia: $1 / 2$ é a chance; $1 / 1$ é em função da retirada.

17 Paulo: Gildete, o que você decide: $1 / 1$ ou $1 / 2$ ?

18 Gildete: 1/2 é uma bola de duas. Fico com a resposta 1/1 por causa de uma retirada. Se estou errada, ficarei sabendo ((A professora sorril).

Nesta última sequência de diálogos, procuramos retomar o cálculo da probabilidade a partir da perspectiva teórica, ou seja, anterior à fase da experimentação. A repre- 
sentação 1/1 indica a chance de uma extração que envolve a comparação entre o número de casos favoráveis e o número de casos desfavoráveis. 0 raciocínio de Gildete é justificado por meio das seguintes palavras (segmento 10): "A bola que ficou, esquece!" A professora Márcia proferiu a mesma resposta de Gildete, porém não ficou convencida. Sua reação se deu pela proposta de três perguntas (segmento 11). 0 pesquisador novamente incentiva a discussão sobre a avaliação do cálculo da probabilidade na perspectiva teórica (segmento 12). Como resposta, surgiram as representações $1 / 2$ ou $50 \%$. As próprias professoras dão conta de que as representações numéricas $1 / 1$ e $1 / 2$ geraram conflitos cognitivos, devido às concepções probabilísticas em vigor. No entanto, a condução das falas entre os protagonistas foi capaz de gerar a aprendizagem. No caso da fração $1 \frac{1}{2}$, a associação com a probabilidade envolve a concepção clássica. A representação $1 / 1$ indica a chance de uma extração a qual envolve a comparação entre o número de casos favoráveis e o número de retiradas.

\section{Bastidores e cenas do $2^{\circ}$ episódio}

A presença de fenômenos aleatórios em seus resultados ou manifestações é algo que faz parte do cotidiano do ser humano em suas múltiplas relações e interações. A aleatoriedade inerente a muitas situações de nosso cotidiano faz com que tanto as crianças quanto os adultos, independentemente de terem ou não recebido uma educação formal sobre o assunto, tenham um conhecimento intuitivo sobre termos presentes no cotidiano. Pesquisadores como Veses e Cubells (1989), Azcárate e Cardeñoso (1996), Léon (1998) e Barrero (1998) destacam a importância de valorizar os saberes informais que crianças e adultos têm sobre a aleatoriedade, em sua experiência pessoal, para inseri-los numa educação formal de probabilidade. A pesquisa de León (1998), por exemplo, explorou noções sobre conceitos de probabilidade manifestados por alunos iniciantes em uma disciplina de probabilidade e estatística. A autora revelou que esses estudantes, futuros professores de matemática, apresentaram limitações na conceitualização e utilização de termos como aleatório, experimento aleatório, probabilidade e frequência relativa. Esta investigação permitiu revelar conceitualizações em evolução e planejar estratégias de abordagem em sala de aula, de modo que posteriormente eles se sentissem confiantes e capazes de utilizá-las com seus próprios alunos.

Em nossa pesquisa, também valorizamos os possíveis saberes informais sobre a aleatoriedade adquiridos por nossas professoras ao longo de suas experiências pessoais. Apresentamos a seguir a relação das nossas professoras-parceiras com o processo de experimentação com um objeto assimétrico, no caso a tachinha (percevejo). Combinamos inicialmente algumas condições para a realização do experimento: 
a) vinte lançamentos de cada professora; b) para cada registro escrito do resultado obtido, vamos discriminá-lo mediante a possibilidade ponta para cima ou ponta inclinada; c) a aposta no resultado mais provável para ambas, na maioria dos lançamentos, será ponta para cima. De imediato, indagações sobre a forma de pegar

a tachinha surgiram:

19 Gildete: A maneira que você vai lançar não importa?

20 Paulo: A senhora acha que isto interferiria?

21 Gildete: Não sei, acho que não ((risos)).

22 Márcia: De repente, se eu pego assim... I(A professora testa diferentes modos de manusear a tachinhall.

23 Paulo: Se você pegar pela haste da tachinha e a base dela ficar muito próxima do solo, provavelmente os resultados são quase que determinados. Para eliminar qualquer problema, poderíamos chacoalhar o objeto apoiado pelas mãos dispostas em forma de concha e soltar a uma determinada altura, para evitar resultados predeterminados.

Na sequência, realizamos o experimento, cujos resultados foram tabulados a seguir:

Tabela 1 - Frequência de lançamentos da tachinha

\begin{tabular}{|l|c|c|c|c|}
\hline & MÁRCIA & GILDETE & Subtotal & Probabilidade \\
\hline Ponta para cima & 14 & 9 & 23 & $23 / 40=57,5 \%$ \\
\hline Ponta inclinada & 6 & 11 & 17 & $17 / 40=42,5 \%$ \\
\hline
\end{tabular}

Fonte: Tabela elaborada pelos autores.

Após o registro desta tabela na lousa, as professoras tornaram a realizar o experimento, mas sem se preocupar em fazer o registro escrito dos resultados. Diante do fato, questionamos o motivo que as levou àquela atitude, e elas manifestaram que houve uma frustração quanto aos resultados obtidos. A aposta de Gildete foi contrária aos resultados obtidos. Márcia esperava uma margem maior na diferença entre os valores percentuais de probabilidade.

A professora Gildete manifestou interesse em continuar realizando o experimento a partir do pressuposto de que, pegando pela haste a tachinha, estaria aumentando a possibilidade de obter resultados com a ponta voltada para cima. Essa intuição, segundo Gildete, justificou-se pelo fato de que na base da tachinha se concentrava a maior parte da massa do objeto e, sob a interferência da ação da gravidade, ao assentar no solo, o objeto permaneceria com a haste na posição vertical. Incentivamos a conti- 
nuidade do experimento, desde que retomássemos o registro dos resultados obtidos, pois os mesmos seriam fundamentais para o cálculo da probabilidade de cada evento. Para esta etapa do experimento, as professoras não modificaram suas apostas, tendo sido realizadas vinte repetições ao todo. Os resultados apresentados na tabela a seguir contrariam mais uma vez a aposta das professoras:

\section{Tabela 2 - Probabilidade para o experimento da tachinha}

\begin{tabular}{|l|c|c|}
\hline & Subtotal & Probabilidade \\
\hline Ponta para cima & 10 & $10 / 20=50 \%$ \\
\hline Ponta para baixo & 10 & $10 / 20=50 \%$ \\
\hline
\end{tabular}

Fonte: Tabela elaborada pelos autores.

Nas falas a seguir, a crença na superioridade do resultado "ponta para cima" ainda é mantida, mesmo após o término da segunda etapa da realização do mesmo processo de experimentação:

24 Gildete: Eu criei, mas ainda persisto em melhorar a minha tentativa. (A professora acredita que pode manipular os resultados do experimento.)

25 Márcia: É a mesma coisa do estilingue. Se puxar mais, der uma envergadura melhor, a pedra atinge não aquele " $x$ ", mas mais lá para frente.

26 Paulo: E no caso, então, do experimento, você criou uma situação favorável; e o resultado não foi o esperado.

27 Márcia: Ela criou ali. Segundo a Gildete, ela poderia ver a posição da mão, pegar assim (a professora pega a tachinha de diversos modos), mas ela deu uma induzida. Não foi uma induzida?

28 Paulo: Uma induzida no resultado? Você conseguiu o resultado desejado, Gildete?

29 Gildete: Não, mas continuo achando que, se tivesse um esquema bem detalhado, verificando tudo que pudesse nos favorecer, talvez o resultado fosse bom.

30 Paulo: Você acha que poderia ter controle nos resultados?

31 Gildete: É... Não totalmente.

32 Paulo: Ele ainda fica imprevisível?

33 Gildete: É.

Observa-se, no segmento 29, que Gildete tenta controlar tudo que está ao seu alcance, quando diz "(...) continuo achando que, se tivesse um esquema bem detalhado, verificando tudo que pudesse nos favorecer (...)". Ela estava pensando, até aquele 
momento, que poderia controlar tudo, isto é, toda a variação nos resultados do experimento, não aceitando ainda a variação do acaso. A variação do acaso em um experimento, segundo Barbin (2003), representa toda a variação devido a fatores não controláveis. Já Pimentel Gomes (1990), ao definir variação do acaso lou variação aleatória), diz que essa variação é devida a efeitos de fatores que podem ser controláveis ou não. Este mesmo autor complementa afirmando que esses efeitos, sempre presentes nos resultados de um experimento, não podem ser conhecidos individualmente e alteram pouco ou muito os resultados obtidos. Sob esta perspectiva, por mais que haja controle em tudo que está ao nosso alcance, sempre haverá efeitos que não são possíveis de serem controlados, como no caso do experimento das tachinhas, em que Gildete tenta controlar tudo o que pode, e ainda assim obtém resultados aleatórios.

Somente no segmento 31, com a pergunta do pesquisador, é que Gildete começa a aceitar a variação do acaso. Isso é perceptível quando ela responde: “É... não totalmente". Nesse momento, ela percebe que, mesmo que faça tudo o que está ao seu alcance, ainda não é possível prever os resultados. Se o experimento com a tachinha não produz resultados favoráveis, de acordo com a crença das professoras, o contrário acontece com a situação envolvendo a distância percorrida por uma pedra lançada por estilingue, devido ao jeito de manusear o objeto. Gildete propõe uma situação-problema, a qual registramos para complementar as discussões sobre a variação do acaso com base em Barbin (2003) e Pimentel Gomes (1990):

Por exemplo, um bazar que coloque seus produtos, a dona está começando... Ela compra os produtos para colocar no seu bazar analisando a população do bairro, os costumes, o que as pessoas usam e etc. Ela comprou um determinado número e faz uma previsão, comprou 1.000 peças/objetos e prevê vender umas 900 . No final do mês, quando ela for fazer o balanço, ela poderá obter um resultado abaixo de 900 ou acima de 900 , não é isso? Daí, por exemplo, ela obteve abaixo de 900 - não foi o que ela esperava! Acima, tudo bem, é até melhor. E abaixo, o que ela vai fazer? Ela vai novamente tentar melhorar, analisar o foi que aconteceu: a procura, qual foi o produto mais procurado ou não, a qualidade do artigo e etc. Ela não vai procurar melhorar, neste sentido? (professora Gildete).

Este é um experimento não totalmente aleatório, ou seja, a variação nas vendas não é totalmente aleatória. Neste exemplo, parte das vendas é explicada pelos costumes, pelo que as pessoas usam, entre outros fatores, mas parte delas é aleatório. Quando Gildete diz: "Ela vai novamente tentar melhorar, analisar o foi que aconteceu: a procura, qual foi o produto mais procurado ou não, a qualidade do artigo (...)", na verdade ela 
está dizendo, em outras palavras, que vai tentar explicar os fatores que interferiram na variabilidade das vendas. No entanto, dificilmente ela conseguirá prever o valor exato das vendas para o próximo mês, por causa dos fatores que ela não consegue controlar (variação do acaso). A possibilidade de intervenção sobre resultados probabilísticos foi um ponto marcante nas discussões dos processos de experimentação, desencadeados nessa sessão de estudos. Na sequência de diálogos a seguir, a professora Márcia elabora mais uma situação experimental probabilística, com o objetivo de continuarmos debatendo sobre o controle de resultados obtidos.

34 Márcia: Agora me explica... vamos pensar juntos. Se você pega um giz a uma certa distância e joga este giz deitado, no chão. Em quantas partes ele poderia se quebrar? 35 Gildete: Se você jogar, ele vai cair de qualquer modo.

36 Márcia: Ah, sim. Você joga, e em quantos pedaços ele vai se quebrar?

37 Paulo: Você acha que poderíamos definir, determinar explicitamente esses resultados, ou eles seriam algo aleatório, ou seja, eu não teria controle sobre estes números de partes quebradas?

38 Márcia: Não sei, estou perguntando. Não sei, de repente... Daí que vem jogar assim, jogar assado, a esta altura... (IA professora pega o giz e mostra diferentes maneiras de pegá-lo e soltá-lo)). São experimentos que você vai fazendo para avaliar.

39 Paulo: Você vai ter a probabilidade dos resultados em cima do números de tentativas que você fez. Aí que vem a noção de chance. 0 importante é observar; será que eu consigo obter o controle sobre essas minhas chances?

40 Gildete: Não! Controle total, não. Um resultado um pouco mais determinado é possível.

41 Márcia: Não sei... Eu estou lá no início do túnel ainda.

42 Paulo: Mas não melhorou o conceito de chance?

43 Márcia: Sim, mas eu acho que eu já quero estar pulando alguma coisa. Eu acho que vou chegar em casa e ficar lá tentando, tentando para ver se eu chego a alguma conclusão. É aquele negócio: resposta pronta, é isso, é isso.

44 Paulo: A sua expectativa é, ainda, que você consiga controlar o experimento?

45 Márcia: Não! Aí é que está, você não controla o experimento.

46 Paulo: Então a finalidade de você chegar em casa e querer tentar fazer...

47 Márcia: É para ver se tudo isso que nós estamos discutindo, se... Eu acho que não controla, mas será que não mesmo? Então eu vou tentar mais, para amadurecer esta ideia.

48 Paulo: Você quer pôr à prova de que este controle, realmente, é difícil?

49 Márcia: É igual aqui com a Gildete. Ela tinha chegado a uma conclusão. De repente, se a gente não tentasse, essa conclusão poderia ter permanecido. Eu acho que não permaneceu. 
50 Paulo: Você acha que isso foi importante para você?

51 Márcia: Eu acho que sim, porque eu estava vendo que, pelo fato de um dos lados ((referindo-se à possibilidade de concentração de massa na base do objeto)] ser mais pesado, se isto iria influenciar de alguma forma...

52 Paulo: Então fica uma questão para você pensar...

53 Márcia: Então...

54 Paulo: Que tem a ver com a natureza do objeto. Aqui é a concentração de massa do objeto mais em uma parte do que em outra ((referindo-se às tachinhas)). 0 fato de fazer mais experimentos fortaleceu a sua ideia de que chance está associada ao experimento, onde você não consegue ter um controle predeterminado. Ajudou nisso?

55 Márcia: É, mas é aquele negócio... Eu acho que o meu conhecimento está muito pouco. Por isso que você fica assim, será que é isso mesmo?

A continuidade no processo de identificação de fenômenos probabilísticos (segmento 34) constituiu-se numa ferramenta com potencial de instigar discussões frente à natureza dos fenômenos, ou seja, a dualidade entre o determinismo e o aleatório: “Nossas concepções estocásticas (probabilísticas e estatísticas) estão determinadas, em parte, por suas próprias experiências (intuições primárias) e em parte pelo ensino (intuições secundárias)" (Sáenz-Castro, 1999, p. 50). No decorrer dos diálogos, notamos que a experiência e a bagagem intelectual de cada um é relevante na exposição e partilha de saberes. Porém, este processo não é linear, ele é construído na interação de avanços e retrocessos, como no caso da professora Márcia. Assim como se nos mostra capaz de elaborar e discutir os experimentos, a professora também afirma (segmento 41): “Eu estou lá no início do túnel ainda."

No caso da professora Gildete, observamos a reavaliação de sua crença quanto à possibilidade de controle dos resultados. A respeito do experimento do giz, a indagação do pesquisador sobre o controle dos resultados provocou uma reposta em tom de ponderação (segmento 23): “Não! Controle total, não. Um resultado um pouco mais determinado é possível."

Entre os segmentos 36 e 40, podemos notar a menção ao controle total e ao controle parcial. Parcialmente é possível controlar a variação nos resultados de um experimento. Por exemplo, se jogarmos vários gizes de tamanhos distintos, podemos obter uma variação maior no número de partes do que se jogarmos vários gizes de mesmo tamanho. Podemos controlar o tamanho do giz e, consequentemente, podemos reduzir a variação no número de partes obtida pelo experimento da queda deste objeto. Porém, uma quantidade significativa de giz, todos de mesmo tamanho, produzirá como resultado experimental 
uma variabilidade no número de partes, ou seja, a variabilidade é decorrente do acaso.

Em outro momento (segmento 43), a atitude de Márcia, ao afirmar que vai "chegar em casa e ficar lá tentando", tentando para ver se chega a alguma conclusão, mostranos o quanto é relevante para a professora o seu envolvimento no processo de realização de experimentos. Como toda experimentação em probabilidade é caracterizada pela irreversibilidade, ou seja, cada resultado obtido no experimento é único e não pode ser reconstituído, torna-se instigante a busca da sistematização de seus próprios saberes. No processo de aprendizagem de Márcia, os conflitos têm-se acentuado à medida que ela reúne condições para compreender o fenômeno da aleatoriedade. Na discussão sobre o experimento com o giz escolar, atestamos a presença de conflitos na relação entre a possibilidade ou não de controlar os resultados. Entre os segmentos 43 a 55 , percebe-se que Márcia não está totalmente convencida de que não pode controlar totalmente o resultado do experimento, mas começa apreender a "ideia de resultado aleatório".

A carência ou ausência de conhecimentos estocásticos, por um lado, não impossibilita a avaliação da natureza aleatória ou determinista de um experimento, porque o nosso cotidiano não se reduz a fenômenos deterministas. Mesmo que as pessoas não tenham tido a oportunidade de uma educação formal sobre temas envolvendo probabilidade e estatística (estocástica), adultos e crianças elaboram um conhecimento prévio e intuitivo sobre a aleatoriedade, a probabilidade e o acaso, temas derivados da incerteza. Por outro lado, em concordância com León (1998), a maioria das pessoas tem uma visão excessivamente determinista do mundo. Em particular, o docente envolvido com o ensino de matemática tem maior contato com temas laritmética e, em menor grau, geometrial que privilegiam a exatidão dos resultados e que refletem o que é considerado primordial para a educação escolar dos estudantes.

Este último bloco de segmentos abrange reflexões acerca do reconhecimento da incerteza e dos critérios de causalidade como argumentações para caracterizar a aleatoriedade de determinados experimentos. Azcárate, Cardeñoso e Porlán (1998, p. 88) realizaram uma exploração inicial dos critérios ou tipos de argumentos que os sujeitos utilizaram para explicar as situações aleatórias, “a partir de um estudo empírico que incluiu aplicação de um questionário a 57 futuros professores primários, sem instrução prévia sobre o tema". Os argumentos construídos por estes autores foram baseados no reconhecimento da incerteza (sucessos que podem ou não ocorrer, sem maior análise das características do fenômeno) e nos critérios de causalidade (tipo de explicação que reflete um domínio da análise de causa em seus raciocínios, o qual reflete o poder da visão determinista da realidade na hora de se enfrentar com situações dominadas pela incertezal. Em nossa pesquisa, o reconhecimento da incerteza foi feito 
por meio da realização efetiva de experimentos. 0 envolvimento das professorasparceiras na experimentação com as tachinhas foi fundamental na transição entre o não reconhecimento e o reconhecimento da aleatoriedade.

\section{Considerações finais}

Desde o primeiro encontro com nossas professoras-parceiras, buscamos oferecer a oportunidade de vivenciar fenômenos que contemplassem a incerteza, ou seja, a impossibilidade de prever a cor da bola a ser extraída, antes de ocorrer efetivamente a extração. Trabalhando nesse experimento, pudemos refletir sobre o fato de haver, no dia a dia, duas categorias de fenômenos, os de natureza determinista e os aleatórios. Sentimos, então, dois tipos de necessidades: um referente ao esclarecimento do significado de termos pertinentes à probabilidade, outro referente à continuidade do processo de experimentação probabilístico, para discutirmos sobre a possibilidade ou não de criação de estratégias de controle dos resultados. A continuidade do trabalho deu-se com o experimento aleatório de lançamento de um percevejo repetidas vezes, quando pudemos debater a eficácia de determinada estratégia aplicada sobre o objeto, na obtenção de determinado resultado. Durante as discussões que fizemos nesse encontro, as professoras-parceiras fizeram referência à noção da concentração de massa para elaborar estratégias de manuseio do percevejo, de modo que thes fosse possível controlar os resultados.

Esses dois episódios visam despertar o leitor, em especial o docente que atua com aulas de matemática nos anos iniciais do ensino fundamental, para que reflita sobre dois aspectos que consideramos de suma importância no desenvolvimento de competências para a aprendizagem de conteúdos pertinentes ao bloco temático Tratamento da Informação: al análise das potencialidades, limitações e implicações do uso de processos de experimentação; b) valorização da necessidade de planejar as condições de execução de um experimento probabilístico. Em relação ao último aspecto, consideramos que este ainda é negligenciado na educação básica. Já se passaram mais de doze anos desde a implantação dos Parâmetros Curriculares Nacionais, por isso clamamos tanto pelo aumento de publicações acadêmicas, ainda em quantidade escassa, quanto por espaços para discussões e reflexões sobre a prática do delineamento experimental nas ações educativas. 


\section{Referências}

ASSUNÇÃO, Maria Madalena Silva. Magistério primário e cotidiano escolar. Campinas, SP: Autores Associados, 1996, v. 53. (Coleção polêmicas do nosso tempo.)

AZCÁRATE, Pilar; CARDEÑOSO, José Maria. El lenguaje del azar. Una vision fenomelogica sobre los juicios probabilisticos. Epsilon, n. 35, p. 165-178, 1996.

PORLÁN, Rafael. Concepciones de futuros profesores de primaria sobre la noción de aleatoriedad. Enseñanza de las ciencias, v. 16, n. 1, p. 85-97, 1998.

BARBIN, Décio. Planejamento e Análise Estatística de Experimentos Agronômicos. Arapongas: Midas, 2003.

BARRERO, Antón Labraña. Azar o casualidad?: una perspectiva cultural desde la escuela. Epsilon, n. 42, p. 449-469, 1998.

BASTOS, M.S. O livro didático nas aulas de matemática: um estudo a partir das concepções dos professores. In: ENCONTRO NACIONAL DE EDUCAC̦ÃO MATEMÁTICA, 8., 2004, Recife. Anais. Universidade Federal de Pernambuco, 2004.

CARVALHO, Dione Lucchesi; OLIVEIRA, Paulo César. Quatro concepções de probabilidade manifestadas por alunos ingressantes na licenciatura de matemática. [CD-ROM]. In: REUNIÃO ANUAL DA ANPED, 25., 2002, Caxambu. Anais. Caxambu, 2002.

COLLARES, Cecília Azevedo Lima; MOYSÉS, Maria Aparecida Affonso; GERALDI, João Wanderley. Educação continuada: a política da descontinuidade. Educação \& Sociedade - Revista quadrimestral de Ciência da Educação/Centro de Estudos Educação e Sociedade (CEDES), 1999, nº 69, p. 202-219.

GUIMARÃES, Gilda et al. A Educação estatística na educação infantil e nos anos iniciais. Zetetiké, v.17, n. 32, p. 11-28, 2009.

LARROSA, Jorge. Notas sobre a experiência e o saber da experiência. Tradução de João Wanderley Geraldi. Revista Brasileira de Educação, n. 19, p. 20-28, 2002.

LÉON, Nelly. Explorando las nociones básicas de probabilidad a nivel superior. Paradigma, v. 19, n. 2, p. 125-143, 1998.

LOPES, Celi Espasandin. Os desafios da educação estatística no Brasil: um olhar a partir do GT12. In: LOPES, Celi Espasandin; COUTINHO, Cileda de Queiroz e Silva; ALMOULOUD, Saddo Ag. (orgs). Estudos e reflexões em educação estatística. Campinas: Mercado de Letras, 2010, p. 47-64 (Série Educação Estatística em focol.

. CARVALHO, Carolina. Literacia estatística na educação básica. In: NACARATO, Adair Mendes; LOPES, Celi Espasandin (orgs). Escritas e Leituras na educação Matemática. Belo Horizonte: Autêntica, 2005, p. 77-92.

. MORAN, Regina Célia Carvalho Pinto. A estatística e a probabilidade através das atividades propostas em alguns livros didáticos brasileiros recomendados para o ensino fundamental. In: CONFERÊNCIA INTERNACIONAL, EXPERIÊNCIAS E PERSPECTIVAS DO ENSINO DA ESTATÍSTICA: desafios para o século XXI, 1, 1999, Florianópolis. Anais... Florianópolis: UFSC/PRESTA/IASE, 1999. 
p. 167-174.

MAGALHÃES, Marcos Nascimento. Probabilidade e Variáveis Aleatórias. 2. ed. São Paulo: Edusp, 2006. MOURA, Manoel Oriosvaldo. (coord.) O estágio na formação compartilhada do professor: retratos de uma experiência. São Paulo: FEUSP, 1999.

NóVOA, Antônio. Diz-me como ensinas, dir-te-ei quem és e vice-versa. In: FAZENDA, Ivani (org). A pesquisa em educação e as transformações do conhecimento. Campinas: Papirus, 1995, p. 29-41. Coleção Práxis.

OLIVEIRA, Paulo César. O processo de aprender noções de Probabilidade e suas relações no cotidiano das séries iniciais do Ensino Fundamental: uma história de parceria. Campinas-SP, 2003. Tese (Doutorado) - Grupo de Pesquisa CEMPEM/PRAPEM, da Faculdade de Educação, Universidade de Campinas (UNICAMP).

PIMENTEL GOMES, Frederico. Curso de Estatística Experimental. 13. ed. São Paulo: Nobel, 1990.

SÁENZ-CASTRO, César. Materiales para la enseñanza de la teoría de probabilidades. Madrid: ediciones de la Universidad Autónoma de Madrid, 1999.

SPINILLO, Alina Galvão. Chance estimates by young children: strategies used in na ordering chance task. In: INTERNATIONAL CONFERENCE FOR THE PSYCHOLOGY OF MATHEMATICS EDUCATION, 21, Lahti, Finland, 1997. Proceedings. Lahti, Finland, 1997, v. 4, p. 182-189.

STEVENSON, William Joseph. Estatística aplicada à administração. Tradução de Alfredo Alves de Farias. São Paulo: Editora Harbra, 1981.

VESES, Eliseo Borras; CUBELLS, Magda Morata. El azar y su aprendizaje. SUMA, v. 3, p. 21-27, 1989. VIEIRA, Sônia. Análise de Variância: ANOVA. São Paulo: Atlas, 2006.

Recebido em novembro de 2011.

Aprovado em janeiro de 2012.

Paulo César Oliveira, doutor em Educação Matemática pela Universidade Estadual de Campinas UNICAMP. Professor Adjunto da Universidade Federal de São Carlos - Campus Sorocaba, atuando em pesquisas com registros de representação semiótica e aulas investigativas, principalmente com geometria e tratamento da informação. E-mail: paulooliveiradufscar.br.

Júlio César Pereira, doutor em Agronomia (Estatística e Experimentação Agronômica) pela Universidade de São Paulo. Professor Adjunto da Universidade Federal de São Carlos, atuando principalmente no seguinte tema: Geoestatística sob o enfoque Bayesiano, com aplicação em ciências agrárias e biológicas. E-mail: julio.pereira.ufscaragmail.com. 